\title{
Adult Neurogenesis in the Central and Peripheral Nervous Systems
}

\author{
Hyun Jung Kim, Woong Sun \\ Department of Anatomy, Korea University College of Medicine, Seoul, Korea
}

\begin{abstract}
Neurogenesis occurs during embryonic development and continues throughout adulthood. Although spontaneous adult neurogenesis is restricted to selective germinal regions, including the subventricular zone and dentate gyrus of the hippocampus, neural stem cells (NSCs) are widely distributed in the central and peripheral nervous systems. Besides their ability to integrate into existing neural networks during physiological conditions, NSCs also proliferate and differentiate in response to injury, thus promising the potential use of endogenous NSCs for the treatment of neuropathological conditions. In this review, we discuss recent progress in the understanding of adult neurogenesis in the brain and peripheral nervous system.
\end{abstract}

Keywords: Adult stem cells; Neural stem cells; Neurogenesis; Central nervous system; Peripheral nervous system

\section{INTRODUCTION}

Neurogenesis, or the production of new neurons, had been considered to occur only during embryonic development, and no new neurons were thought to be added to the adult nervous system. In the past decade, however, this dogma was revised as the constitutive production of new neurons was identified in increasing regions of the adult brain, including the olfactory bulb and dentate gyrus (DG) of the hippocampus [1-4]. Adult neurogenesis was also discovered in the adult peripheral nervous system (PNS) [5].

Although spontaneous adult neurogenesis is somewhat limited to selective germinal regions, cells producing new neurons, i.e., neural stem cells (NSCs), are widely distributed in the central and PNSs. Furthermore, the proliferation of NSCs can be stimulated by injury, thus promising the potential use of endogenous NSCs for the treatment of many neuropathological conditions. In this review, we discuss recent progress in our understanding of adult neurogenesis in the brain and PNS.

\section{DISTRIBUTION OF NEURAL STEM CELLS IN THE BRAIN}

Embryonic neural tissues are first specified from neuroectoderm during early embryogenesis, forming a neural tube. Embryonic NSCs are enriched in the neural tube, and their postnatal remnants reside near the ventricular system [6,7]. Thus, one of the major sources of adult NSCs remains the subventricular zone (SVZ) of the lateral ventricle. The anterior SVZ holds active NSCs that spontaneously provide new neurons to the olfactory bulb via the rostral migratory stream $[1,7,8]$. Whereas most NSCs in the adult brain are closely associated with the ventricular system, hippocampal NSCs are localized in the subgranular zone (SGZ) of the DG apart from ventricles. A subset of NSCs migrates and forms a secondary germinal zone in the hippocampus during embryonic development. The formation of DG occurs mainly during postnatal development, and NSCs in the secondary germinal zone appear to remain in the SGZ, supplying neurons to the existing hippocampal network throughout adulthood $[4,9]$.
Corresponding author: Woong Sun

Department of Anatomy, Korea University Anam Hospital, Korea University College of Medicine, 73 Inchon-ro, Seongbuk-gu, Seoul 136-705, Korea

TEL: +82-2-880-5114 / FAX: +82-32-460-8340 / E-mail: woongsun@korea.ac.kr

Submitted: May 4, 2012 / Accepted after revision: June 20, 2012
This is an Open Access article distributed under the terms of the Creative Commons Attribution Non-Commercial License (http://creativecommons.org/licenses/by-nc/3.0/) which permits unrestricted non-commercial use, distribution, and reproduction in any medium, provided the original work is properly cited. 
Similar to the SVZ, different types of NSCs exist along the ventricular system, including the $3 \mathrm{rd}$ and 4 th ventricles of the brain, and the central canal of the spinal cord [10-12]. However, NSCs in these regions appear to be quiescent, and they neither proliferate nor spontaneously produce new neurons in the adult brain [3]. An extended and collapsed area of lateral ventricles called the subcallosal zone (SCZ) also contains NSCs that have the potential to produce neuroblasts [13]. Recently, we found that newly produced neuroblasts in the SCZ fail to mature into functional neurons and undergo massive programmed cell death [14]. Thus, gene knockout of Bax, a pro-apoptotic gene, completely rescues SCZ neuroblasts from death and results in the generation of neurons. This result indicates that the SCZ does not provide a sufficient environment for the maturation of neuroblasts into neurons.

In this respect, NSCs in the adult brain may be classified into 3 categories on the basis of their spontaneous ability to proliferate and differentiate. The first class of cells are the NSCs in the SVZ and DG. These two populations of NSCs within the SVZ and SGZ spontaneously produce new neurons for the adult olfactory bulb and DG, respectively. The second class of NSCs is in the SCZ; these cells proliferate and produce neuroblasts but do not mature into neurons. Considering that both SCZ and SVZ NSCs can produce neurons in vitro [1,13], it appears that the environment surrounding these stem cells plays a role in the regulation of neuronal maturation. Whereas the SVZ promotes the proliferation and differentiation of NSCs, the SCZ and its surrounding white matter fail to provide a favorable environment for neuronal maturation, resulting in the programmed cell death of newly generated neuroblasts.

Lastly, NSCs in other brain regions rarely proliferate and appear to be maintained as a dormant form; these other regions include the neocortex, striatum, amygdala, and substantia nigra [15-18]. Due to their limited capacity to proliferate under normal physiological conditions, the existence of NSCs in these regions was only confirmed by neurosphere formation in vitro. The significance of NSCs in these regions may be related to the injury response and regeneration.

In addition to the brain, the ganglia of the PNS contain NSCs. The PNS is primarily formed by neural crest stem cells (NCSCs) during embryonic development [5], and these cells remain in the adult ganglion $[19,20]$. The NSCs cannot spontaneously produce neuronal or glial cells, but they respond to injury and produce neuronal cells for regeneration. In this respect, the NSCs of the PNS can be also classified into the third class. The significance and regulation of adult neurogenesis in the PNS will be discussed later.

\section{FUNCTION OF NEUROGENESIS IN THE BRAIN}

It is puzzling why the NSCs in specialized brain regions maintain neurogenic potentials. It has been proposed that adult neurogenesis alters existing neural networks, which could jeopardize the stability of brain function [21]. Thus, the addition of new neurons is allowed only in limited brain regions such as the olfactory bulb and hippocampus [22,23]. The role of adult neurogenesis has been extensively studied with the use of genetic models. Selective ablation of adult NSCs results in the impairment of selective brain functions related to the olfactory bulb and hippocampus. For instance, inhibition of hippocampal neurogenesis impairs associative learning processes such as spatial memory and contextual fear conditioning [24-26]. On the other hand, spatial learning as measured by the Morris water maze test failed to exhibit a significant defect $[27,28]$, which suggests that adult neurogenesis contributes to partial aspects of hippocampal functions. Similarly, ablation of olfactory neurogenesis affects pheromone responses, whereas olfactory functions are largely spared $[26,29,30]$. In fact, this result was somewhat unexpected because the addition of new neurons occurs only in the main olfactory bulbs, which are not known to mediate pheromone responses. This implies that newly produced neurons may directly integrate into the pheromone-response circuits or may indirectly influence the vomeronasal neural circuit.

Besides their role in the production of functional cells during the normal or regenerative condition, adult NSCs may be a good source for secretory factors affecting brain function. Transplantation experiments have provided some insights into this. It is known that brain damage is improved after transplantation of NSCs or other stem cells from different sources [31-33]. However, these beneficial effects are not mediated by the addition of new functional neurons but by the secretion of factors promoting regenerative processes of host tissues. Therefore, neurogenesis might also operate similarly in vivo.

In this respect, NSCs in the SCZ could play a significant role in the control of white matter development. We have tested the time-course changes in neuroblast formation during postnatal development [34]. Interestingly, neuroblast formation was active until juvenile periods (1 to 3 months) in the SCZ but was rapidly reduced during the period of 3 to 6 months. Consider- 
ing that SVZ and DG neurogenesis is evident although reduced in aged ( 1 to 2 years old) mice, such rapid depletion may be related to the termination of white matter development. Because Doublecortin-expressing neuroblasts seldom trans-differentiate into oligodendrocytes [35], a plausible mechanism underlying the possible involvement of SCZ neuroblast formation and white matter development is mediated by secretory factors released from neuroblasts. Further experiments would clarify this intriguing issue.

\section{NEUROGENESIS IN THE PNS}

Increasing evidence suggests the presence of NSCs in the adult PNS. Unlike in the central nervous system (CNS), neurons and glial cells in the PNS are all derived from neural crest during embryonic development $[5,36]$. The NCSCs are found in the adult dorsal root ganglion (DRG), trigeminal ganglion, and enteric nervous system $[19,20,37]$. The increase in body size during postnatal development requires more sensory ganglion neurons for efficient nerve control. Accordingly, in the rat, the number of DRG neurons progressively increases during postnatal development [38]. This increase in neuron numbers in the postnatal DRG supports the presence of NCSCs in the DRG. In vitro, cells that can form neurospheres were isolated from these sensory ganglia, and these cells exhibited typical markers for embryonic NCSCs, such as nestin and p75 neurotrophin receptor (p75NTR) expression [20]. They could be differentiated into neurons, glia, and smooth muscle cells, which can be produced from neural crest in vivo.

NCSC-like cells were also isolated from adult enteric nervous system, and these cells expressed glial fibrillary acidic protein, which suggests that they exhibit glia-like characteristics similarly to the NSCs of the CNS. Importantly, the neurogenic potential of enteric NCSCs can be activated to produce new neurons upon nerve injury [37]. Although direct evidence is missing, increased enteric neurogenesis may a play critical role in the regeneration of damaged PNS. However, it is still unknown whether newly produced PNS neurons can be integrated into the existing neural circuits.

\section{CLINICAL IMPLICATIONS}

The presence of adult NSCs and spontaneous neurogenesis provide great hope for curing brain diseases and for recovery from brain damage. For instance, increased proliferation of NSCs and subsequent generation of neural cells may be enhanced for the regeneration of the injured nervous system. It is well known that brain injury promotes the proliferation of nearby NSCs, generating more neural cells including astrocytes and neurons [39]. For example, focal ischemia transiently induces forebrain SVZ cell proliferation and neurogenesis [40,41]. The NSCs in the SVZ and DG are also stimulated after traumatic brain injury [42,43], and these data suggest that adult neurogenesis may play a role in the self-recovery mechanism of the brain. However, the amount of spontaneously produced neuroblasts after brain injury is highly limited, and the survival and differentiation of them into mature neurons are far from exhibiting regenerative effects.

In this respect, engineering NSCs to modify their properties may enhance the neurogenic potential of endogenous stem cells. Viral infection of specific genes is an efficient way to introduce new characters to the stem cells. Because retrovirus infects only proliferating cells such as NSCs, retroviral gene delivery has been successfully applied for this purpose [44]. Attempts to produce directed cell types have also been successful, and the introduction of transcriptional factor Mash1 into NSCs in the DG promoted the production of oligodendrocytes, whereas NSCs in the DG normally produce neurons and astrocytes [45]. Alternatively, the injection of a chemical or small compound can also alter the endogenous signaling of stem cell differentiation. Treatment with histone deacetylase inhibitors, for instance, was shown to perturb endogenous gene expression patterns and modified the differentiation of NSC-derived cells [46]. Addition of strong morphogens such as Wnt, Shh, and Fgfs also led to changes in cell fate [47-49], which suggests that small compounds can be developed for modifying the proliferation and differentiation of endogenous NSCs.

Impairment of spontaneous neurogenesis may be involved in brain disease [50]. This idea was first examined in the animal model of Parkinson's disease (PD). In the rat, a subset of midbrain dopaminergic neurons undergoes spontaneous programmed cell death and is replaced by a new subset [15]. Thus, an imbalance in the self-renewal process may directly cause PD. However, we and others failed to replicate this experiment in mice and rats, and further evaluations are required [51,52]. More recently, Perera et al.'s report [53] demonstrated that the effect of antidepressant fluoxetine is mediated by increased neurogenesis, thus promoting the idea that depression may be caused by reduced adult neurogenesis. Considering that standard animal housing conditions are in fact deprived conditions compared with the natural habitat of mice, this result should be interpret- 
ed with caution, however, and examination under more natural settings is required.

The identification of adult NSCs has opened a new door for novel treatments for the repair of already damaged neural tissues in the central and PNSs. Although our understanding of NSCs is still rather elementary, many researchers are trying to characterize the cellular mechanisms that guide the cell fate and behavior of stem cells. In the near future, cumulative studies will provide an efficient way to manipulate endogenous NSCs for therapeutic applications.

\section{CONFLICT OF INTEREST}

No potential conflict of interest relevant to this article was reported.

\section{REFERENCES}

1. Lois C, Alvarez-Buylla A. Proliferating subventricular zone cells in the adult mammalian forebrain can differentiate into neurons and glia. Proc Natl Acad Sci U S A 1993;90:2074-7.

2. Reynolds BA, Weiss S. Generation of neurons and astrocytes from isolated cells of the adult mammalian central nervous system. Science 1992;255:1707-10.

3. Gould E. How widespread is adult neurogenesis in mammals? Nat Rev Neurosci 2007;8:481-8.

4. Palmer TD, Takahashi J, Gage FH. The adult rat hippocampus contains primordial neural stem cells. Mol Cell Neurosci 1997;8:389-404.

5. Stemple DL, Anderson DJ. Isolation of a stem cell for neurons and glia from the mammalian neural crest. Cell 1992;71:973-85.

6. Kalyani A, Hobson K, Rao MS. Neuroepithelial stem cells from the embryonic spinal cord: isolation, characterization, and clonal analysis. Dev Biol 1997;186:202-23.

7. Luskin MB. Restricted proliferation and migration of postnatally generated neurons derived from the forebrain subventricular zone. Neuron 1993;11:173-89.

8. Kornack DR, Rakic $\mathrm{P}$. The generation, migration, and differentiation of olfactory neurons in the adult primate brain. Proc Natl Acad Sci U S A 2001;98:4752-7.

9. Song HJ, Stevens CF, Gage FH. Neural stem cells from adult hippocampus develop essential properties of functional CNS neurons. Nat Neurosci 2002;5:438-45.

10. Xu Y, Tamamaki N, Noda T, Kimura K, Itokazu Y, Matsumoto N, et al. Neurogenesis in the ependymal layer of the adult rat 3rd ventricle. Exp Neurol 2005;192:251-64.
11. Weiss S, Dunne C, Hewson J, Wohl C, Wheatley M, Peterson AC, et al. Multipotent CNS stem cells are present in the adult mammalian spinal cord and ventricular neuroaxis. J Neurosci 1996;16: 7599-609.

12. Martens DJ, Seaberg RM, van der Kooy D. In vivo infusions of exogenous growth factors into the fourth ventricle of the adult mouse brain increase the proliferation of neural progenitors around the fourth ventricle and the central canal of the spinal cord. Eur J Neurosci 2002;16:1045-57.

13. Seri B, Herrera DG, Gritti A, Ferron S, Collado L, Vescovi A, et al. Composition and organization of the SCZ: a large germinal layer containing neural stem cells in the adult mammalian brain. Cereb Cortex 2006;16 Suppl 1:103-11.

14. Kim WR, Chun SK, Kim TW, Kim H, Ono K, Takebayashi H, et al. Evidence for the spontaneous production but massive programmed cell death of new neurons in the subcallosal zone of the postnatal mouse brain. Eur J Neurosci 2011;33:599-611.

15. Zhao M, Momma S, Delfani K, Carlen M, Cassidy RM, Johansson $\mathrm{CB}$, et al. Evidence for neurogenesis in the adult mammalian substantia nigra. Proc Natl Acad Sci U S A 2003;100:7925-30.

16. Bernier PJ, Bedard A, Vinet J, Levesque M, Parent A. Newly generated neurons in the amygdala and adjoining cortex of adult primates. Proc Natl Acad Sci U S A 2002;99:11464-9.

17. Dayer AG, Cleaver KM, Abouantoun T, Cameron HA. New GABAergic interneurons in the adult neocortex and striatum are generated from different precursors. J Cell Biol 2005;168:415-27.

18. Gould E, Reeves AJ, Graziano MS, Gross CG. Neurogenesis in the neocortex of adult primates. Science 1999;286:548-52.

19. Lagares A, Li HY, Zhou XF, Avendano C. Primary sensory neuron addition in the adult rat trigeminal ganglion: evidence for neural crest glio-neuronal precursor maturation. J Neurosci 2007;27:7939-53.

20. Li HY, Say EH, Zhou XF. Isolation and characterization of neural crest progenitors from adult dorsal root ganglia. Stem Cells 2007; 25:2053-65.

21. Kempermann G. Why new neurons? Possible functions for adult hippocampal neurogenesis. J Neurosci 2002;22:635-8.

22. Carleton A, Petreanu LT, Lansford R, Alvarez-Buylla A, Lledo PM. Becoming a new neuron in the adult olfactory bulb. Nat Neurosci 2003;6:507-18.

23. Toni N, Laplagne DA, Zhao C, Lombardi G, Ribak CE, Gage FH, et al. Neurons born in the adult dentate gyrus form functional synapses with target cells. Nat Neurosci 2008;11:901-7.

24. Dupret D, Revest JM, Koehl M, Ichas F, De Giorgi F, Costet P, et al. Spatial relational memory requires hippocampal adult neurogenesis. PLoS One 2008;3:e1959. 
25. Saxe MD, Battaglia F, Wang JW, Malleret G, David DJ, Monckton JE, et al. Ablation of hippocampal neurogenesis impairs contextual fear conditioning and synaptic plasticity in the dentate gyrus. Proc Natl Acad Sci U S A 2006;103:17501-6.

26. Imayoshi I, Sakamoto M, Ohtsuka T, Takao K, Miyakawa T, Yamaguchi $\mathrm{M}$, et al. Roles of continuous neurogenesis in the structural and functional integrity of the adult forebrain. Nat Neurosci 2008; 11:1153-61.

27. Kim WR, Park OH, Choi S, Choi SY, Park SK, Lee KJ, et al. The maintenance of specific aspects of neuronal function and behavior is dependent on programmed cell death of adult-generated neurons in the dentate gyrus. Eur J Neurosci 2009;29:1408-21.

28. Lee JW, Kim WR, Sun W, Jung MW. Role of dentate gyrus in aligning internal spatial map to external landmark. Learn Mem 2009;16: 530-6.

29. Sakamoto M, Imayoshi I, Ohtsuka T, Yamaguchi M, Mori K, Kageyama R. et al. Continuous neurogenesis in the adult forebrain is required for innate olfactory responses. Proc Natl Acad Sci U S A 2011;108:8479-84.

30. Kim WR, Kim Y, Eun B, Park OH, Kim H, Kim K, et al. Impaired migration in the rostral migratory stream but spared olfactory function after the elimination of programmed cell death in Bax knock-out mice. J Neurosci 2007;27:14392-403.

31. Englund U, Bjorklund A, Wictorin K, Lindvall O, Kokaia M. Grafted neural stem cells develop into functional pyramidal neurons and integrate into host cortical circuitry. Proc Natl Acad Sci U S A 2002;99:17089-94.

32. Horner PJ, Gage FH. Regenerating the damaged central nervous system. Nature 2000;407:963-70.

33. Hallbergson AF, Gnatenco C, Peterson DA. Neurogenesis and brain injury: managing a renewable resource for repair. J Clin Invest 2003;112:1128-33.

34. Kim HJ, Kim JY, Sun W. Age-dependent changes in the subcallosal zone neurogenesis of mice. Neurochem Int 2012 Mar 6 [Epub]. http://dx.doi.org/10.1016/j.neuint.2012.02.027.

35. Jablonska B, Aguirre A, Raymond M, Szabo G, Kitabatake Y, Sailor KA, et al. Chordin-induced lineage plasticity of adult SVZ neuroblasts after demyelination. Nat Neurosci 2010;13:541-50.

36. Dupin E, Calloni G, Real C, Goncalves-Trentin A, Le Douarin NM. Neural crest progenitors and stem cells. C R Biol 2007;330:521-9.

37. Laranjeira C, Sandgren K, Kessaris N, Richardson W, Potocnik A, Vanden Berghe P, et al. Glial cells in the mouse enteric nervous system can undergo neurogenesis in response to injury. J Clin Invest 2011;121:3412-24.

38. Namaka MP, Sawchuk M, MacDonald SC, Jordan LM, Hochman S.
Neurogenesis in postnatal mouse dorsal root ganglia. Exp Neurol 2001;172:60-9.

39. Kernie SG, Parent JM. Forebrain neurogenesis after focal Ischemic and traumatic brain injury. Neurobiol Dis 2010;37:267-74.

40. Arvidsson A, Collin T, Kirik D, Kokaia Z, Lindvall O. Neuronal replacement from endogenous precursors in the adult brain after stroke. Nat Med 2002;8:963-70.

41. Parent JM, Vexler ZS, Gong C, Derugin N, Ferriero DM. Rat forebrain neurogenesis and striatal neuron replacement after focal stroke. Ann Neurol 2002;52:802-13.

42. Richardson RM, Sun D, Bullock MR. Neurogenesis after traumatic brain injury. Neurosurg Clin N Am 2007;18:169-81, xi.

43. Chirumamilla S, Sun D, Bullock MR, Colello RJ. Traumatic brain injury induced cell proliferation in the adult mammalian central nervous system. J Neurotrauma 2002;19:693-703.

44. van Praag H, Schinder AF, Christie BR, Toni N, Palmer TD, Gage FH. Functional neurogenesis in the adult hippocampus. Nature 2002;415:1030-4.

45. Jessberger S, Toni N, Clemenson GD Jr, Ray J, Gage FH. Directed differentiation of hippocampal stem/progenitor cells in the adult brain. Nat Neurosci 2008;11:888-93.

46. Hsieh J, Nakashima K, Kuwabara T, Mejia E, Gage FH. Histone deacetylase inhibition-mediated neuronal differentiation of multipotent adult neural progenitor cells. Proc Natl Acad Sci U S A 2004; 101:16659-64.

47. Lie DC, Colamarino SA, Song HJ, Desire L, Mira H, Consiglio A, et al. Wnt signalling regulates adult hippocampal neurogenesis. Nature 2005;437:1370-5.

48. Lai K, Kaspar BK, Gage FH, Schaffer DV. Sonic hedgehog regulates adult neural progenitor proliferation in vitro and in vivo. Nat Neurosci 2003;6:21-7.

49. Song H, Stevens CF, Gage FH. Astroglia induce neurogenesis from adult neural stem cells. Nature 2002;417:39-44.

50. Winner B, Kohl Z, Gage FH. Neurodegenerative disease and adult neurogenesis. Eur J Neurosci 2011;33:1139-51.

51. Kim TW, Kim H, Sun W. Effects of 6-hydroxydopamine on the adult neurogenesis of dopaminergic neurons in the mouse midbrain. Exp Neurobiol 2009;18:26-31.

52. Frielingsdorf H, Schwarz K, Brundin P, Mohapel P. No evidence for new dopaminergic neurons in the adult mammalian substantia nigra. Proc Natl Acad Sci U S A 2004;101:10177-82.

53. Perera TD, Dwork AJ, Keegan KA, Thirumangalakudi L, Lipira $\mathrm{CM}$, Joyce $\mathrm{N}$, et al. Necessity of hippocampal neurogenesis for the therapeutic action of antidepressants in adult nonhuman primates. PLoS One 2011;6:e17600. 